\title{
9
}

\section{Real World Learning: Simulation and Gaming}

\section{Jonathan Lean, Jonathan Moizer, Cathrine Derham, Lesley Strachan, and Zakirul Bhuiyan}

\section{Introduction}

Simulations and games have become increasingly popular methods of teaching and learning within the Higher Education sector over recent years (Lean, Moizer, \& Warren, 2015; Moizer \& Lean, 2010). They have been used in subject areas as diverse as entrepreneurship (Newbery, Lean, Moizer, \& Haddoud, 2018), history (McCall, 2016) and nursing (Koivisto et al., 2018). Simulations and games enable the learner to gain

J. Lean $(\bowtie) \cdot$ J. Moizer

University of Plymouth, Plymouth, UK

e-mail: jonathan.lean@plymouth.ac.uk

C. Derham

University of Surrey, Guildford, UK

L. Strachan

SimVenture, York, UK

Z. Bhuiyan

Solent University, Southampton, UK

(C) The Author(s) 2021

D. A. Morley, M. G. Jamil (eds.), Applied Pedagogies for Higher Education, https://doi.org/10.1007/978-3-030-46951-1_9 
insight into real world situations in an authentic and engaging way without the need to leave the classroom. They allow students to experiment and see the impact of their decisions and actions within a safe environment and without any real world consequences. Hence, they offer valuable insights into contexts that may be difficult for students to experience directly in the real world due to the level of risk, the cost or the timescale involved.

This chapter aims to review the role of simulations and games as proxies for real world learning. The structure and focus of the chapter draws on a concept-mapping exercise undertaken with the book editors as part of the development of this publication (see Fig. 9.1). In the sections that follow, the nature of simulations and games is first discussed with reference to examples in higher education. Next, the position of simulations and games within the field of real world learning is explored, emphasising their potential to contribute to and extend the learning experience of higher education students. Their learning benefits are then evaluated along with some of the challenges associated with their use. Three case studies illustrating the use and value of simulations and games in a range of subject disciplines are presented. The chapter concludes by considering

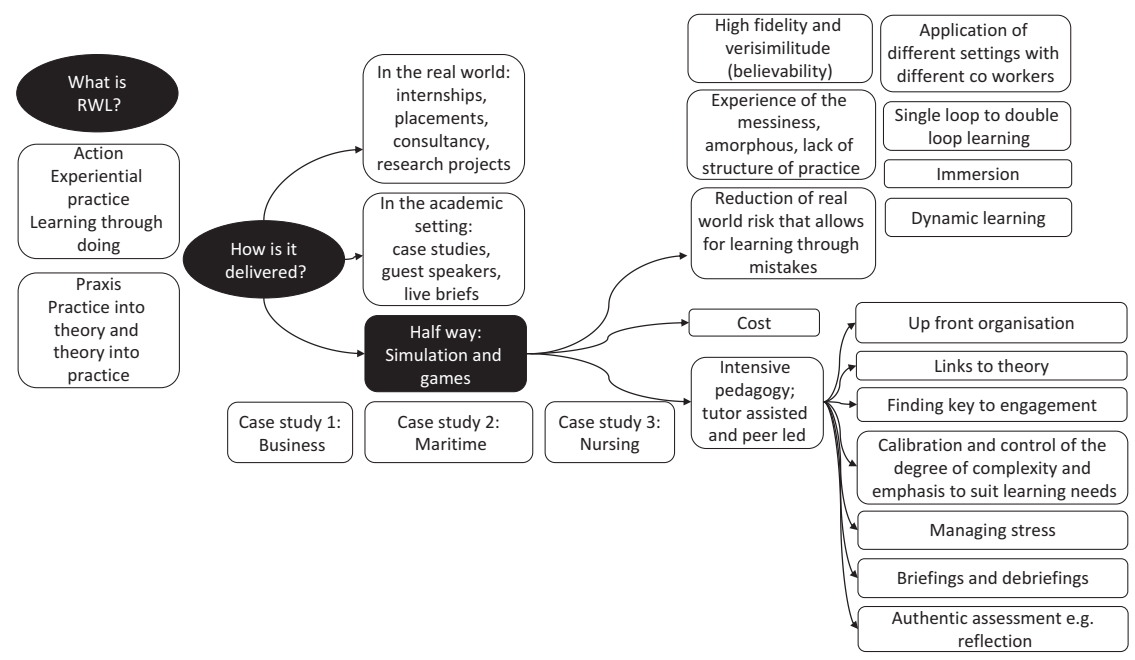

Fig. 9.1 Concept map from the authors 
key implications for educational practice and areas for future research and pedagogical development.

\section{The Nature of Simulation and Gaming and Its Role in Real World Learning}

The use of simulations and games in higher education has gained increasing attention in recent years as such learning techniques have increasingly become normal features of academic programmes across a range of subject disciplines (Baptista \& Oliveira, 2018; Hainey, Connolly, Stansfield, \& Boyle, 2011; Ibrahim, Masrom, Yusoff, Zainuddin, \& Rizman, 2017; Moizer \& Lean, 2010; Subhash \& Cudney, 2018; Wouters \& van Oostendorp, 2017). Whilst much current attention has been on the growth in the use of computer-based 'serious games' (Boyle et al., 2016), the nature and variety of simulation and gaming approaches continue to become richer and more diverse. Techniques range from highly sophisticated online serious games that allow students to immerse themselves in a computer-generated world to more traditional approaches such as roleplays where students play characters within a classroom setting. Lean, Moizer, Towler, and Abbey (2006) demonstrate the diversity of approaches available to educators by developing a typology of simulations and games that distinguishes between those that are computer-based (including gaming simulations, training simulations and modelling simulations) and non-computer-based (including role-plays and educational games, such as board games and paper-based games). Hence, simulations and games can take many varied forms, providing a very wide range of options to support student learning.

Whatever the exact nature of the simulations or games used by educators, what they share in common is that they attempt to imitate or represent some form of real world phenomenon, process or entity. In the context of real world learning, simulations and games therefore hold a unique position and play a very particular role. By definition, simulations and games do not involve direct engagement in real world situations; rather they imitate aspects of the real world to facilitate learning. For 
instance, a computer-based business simulation game may allow students to go through the process of making decisions on aspects of marketing, finance and production for a 'virtual' company to compete with other virtual companies and to see the results of these decisions without any engagement at all with real companies or industrial settings. Similarly, a legal role-play may allow law students to experience legal processes and develop client representation skills without setting foot in a courtroom. Therefore, from a pedagogical perspective, simulations and games occupy a space that sits between the classroom and the real world.

Given that simulations and games may be considered a 'half way house' between traditional classroom learning and real world learning, it could be argued that they are in some ways less valuable or effective than learning that is fully embedded in real world activity. However, simulations and games typically seek to imitate real world phenomena and processes that, for various reasons, are difficult for students to experience in an actual real world setting. Therefore, they can be considered an important link between theories espoused in the lecture hall and the real world.

Most commonly, the reasons for employing a simulation or game instead of a learning experience set fully in the real world relate to issues of risk, cost or timescale or a combination of two or more of these factors. In the real world, some activities may be judged to present too much of a risk to be suitable as a learning approach. Such risks may be to the students themselves, other people or property/resources. For example, Human Patient Simulators are sophisticated software-facilitated manikins that are used in medical education to enable medical students to undertake procedures without the risk of harming real patients (Al-Elq, 2010; Hogg et al., 2019). The cost of undertaking certain real world activities with students may be considered prohibitive, meaning that simulation-based approaches are attractive and useful. For instance, the 'Bridge Simulation' used at Solent University in the UK to train students in the field of maritime navigation is cost effective compared to using real ships to develop the required knowledge and skills (see Case Study 1). Finally, the timescale required to undertake some activities in the real world is impractical in the context of educational programmes where modules of study may only run for a period of 10-15 weeks. A particular advantage of simulations is that time can be compressed. For example, in 
a computer-based business simulation, decisions and financial result cycles that may stretch out over several years in the real world can be played out by students over a few days or weeks. The ability to operate in simulated time rather than real world time opens up possibilities for learning that may not otherwise be possible.

\section{Case Study 1}

Bridge Simulation-Changing Behaviours for Enhanced Actions (Zakirul Bhuiyan, Senior Lecturer in Ship Simulation, Southampton Solent University, UK)

Shipping is the key to the global economy with the majority of maritime transport operations being carried out by seafarers. Seafarers need to be competent, experienced, skilled and knowledgeable as shipping is a highly technical and professional discipline. Many of the operational mistakes, emergencies and critical situations that have occurred on board ships have been attributed to human error, usually as a result of incompetence and lack of training and education (Barnett, 2004). Bridge simulation is a system commonly used in marine navigational training to enable ship navigating officers to develop their knowledge and experience of operational skills such as ship navigation, collision avoidance and ship handling skills, both in open seas and confined waters. It involves virtual representations of real ships as well as surrounding environmental conditions and geographical areas. Its versatile and realistic functionalities have expanded the scope of maritime training to encompass both operational seafaring skills and behavioural skills such as leadership and management.

Bridge simulation enables the creation of dynamic, real-life situations in a controlled classroom environment where navigating officers can practice new techniques and skills and obtain insights from instructors and peers. Students transfer their theories to real world situations in a risk-free operating environment. They deal with multiple problems and learn to prioritise multiple tasks under similar high stress, changing conditions (including environmental conditions such as weather) to those in actual ship-board operations. Each ship officer's performance is evaluated holistically to make a formal assessment of competence in a variety of 
simulation scenarios. This training can be described through three major theoretical paradigms of learning. Firstly, the competence-based and training-focused professional learning activities which can be defined as a behaviourist approach (Pavlov, 2010; Skinner, 2011). Secondly, the maritime profession and associated education involve various critical thinking, problem-solving, decision-making and situation analysis activities which refer to the theories of the cognitive domain (Hollon \& Beck, 1994). Thirdly, the discussion-based, shared and professional communitydriven working environment is where the application of constructive approaches to learning is made (Vygotsky, 1978).

The most important part of a training session is the debriefing, which is conducted at the end of each simulation exercise when the saved exercise is replayed for the reflections of both the seafarers and instructors. Debriefing is the key to the entire learning process, during which trainees' knowledge and attitudes are applied, evaluated and synthesised (Ellman, 1977) and this process integrates the simulation experience into the learning environment (Gatfield, 2006). During the debriefing session, trainees, peers and instructors critically examine and comment on what went wrong, what could be learned and improved and so forth. Trainees have the freedom to express themselves and they need to justify their actions. Furthermore, the relationship between students and instructors replicates the real-life relationship between professionals. Learning is all about change-change brought about by the development of skills, understanding something new and/or changing an attitude. Therefore, feedback in the form of debriefing can be a powerful motivator to learning.

During the simulation training, lecturers suggest that the seafarers follow the upper stages of Bloom's taxonomy (problem solving, critical thinking, analysis, evaluation) in the reflection and development of their active learning (Bloom, 1956). The reflection processes involve questioning from the learner, collaborative activities and application of learning in the practical field. Because of the process-driven and applied features of the reflections, the assessment is predominantly subjective for this type of activity, against a range of competency-based objectives. Learners compare their current progress against desired goals, resulting in changes to their motivation and self-perception of ability (Nicol \& 
Macfarlane-Dick, 2006) and it narrows the gap between their current and desired levels of achievement and having a positive effect on behaviours, emotions and beliefs.

Although simulation courses are offered at many higher educational institutions, their educational features are under-researched (Pallis $\& \mathrm{Ng}$, 2011). The nature and procedures of simulation training activities are similar to traditional professional training programmes as they predominantly involve skills-based repetitive actions. Therefore, the question may arise of whether simulation programmes can fit into traditional higher education curricula which greatly emphasise progression-driven and research-integrated educational approaches for deep and meaningful learning (Stern, 2016). The query is largely unanswered as the pedagogical aspects of simulation training are still under-researched. This knowledge gap creates scope for exploring the pedagogical aspects of training, for example, its instructional strategies, learning outcomes and student engagement. Maritime simulation training programmes are required to fit traditional and typical higher education curricula; there is a need for lecturers to link professionalism, research and interpersonal skills to develop excellence in their teaching practices. Moreover, this promotes an enthusiasm for learning and encourages the maritime community to set its sights higher with a view to translating maritime education practices for the wider higher education community. Bridge simulation training is tightly regulated (nationally and internationally) and also competence based. How these factors fit into higher education frameworks is a topic requiring further research if bridge simulation training is to work successfully in a multidimensional education environment.

It is evident that simulations and games address many of the key limitations of some forms of real world learning by overcoming the issues of risk, cost and timescale. In doing so, simulations and games considerably extend the scope of real world learning by facilitating learning experiences that may not otherwise be accessible to students. Simulations and games may not offer the same level of insight into the real world as some other forms of learning that are fully embedded in actual professional practice settings. However, due to their particular strengths and characteristics, they provide educators with valuable options for engaging students in impactful experiential learning activities. In the next section, 
further benefits of simulation and gaming are explored, alongside some of the challenges associated with their use.

\section{Benefits of Simulations and Games for Real World Learning}

A feature of real world learning is that it allows students to experience the complex, amorphous and sometimes messy nature of practice within professional or work-related settings (McGrath, Harris, \& Whitelaw, 2016; Tai, Canny, Haines, \& Molloy, 2017). Simulations and games aim to mirror such contexts by enabling students to learn about the realities of practice but within a more controlled environment. Learners are able to develop highly relevant work-related skills and 'pre-experience' different forms of activity before real world engagement (Goi, 2019; Strachan, 2016). Thus, simulations and games support employability whilst also promoting deeper learning (Marda, Economou, \& Bouki, 2018; Narayanan \& Turner, 2019; Scholtz \& Hughes, 2019). Case Study 2 reports on research relating to the impact of a business simulation on the self-perceived employability skills of students.

\section{Case Study 2}

Can a Business Simulation Game Develop Students' Employability Skills? (Lesley Strachan, Learning and Development Manager, SimVenture)

This case study evaluates the use of a serious business simulation game (SimVenture Evolution) to develop employability skills. Business simulation games have been engaged as a pedagogic tool for over 50 years to create effective experiential learning opportunities (Keys \& Wolfe, 1990). Simulation games also have the potential to encourage employability skills (Gopinath \& Sawyer, 1999). Clarke (2009) identified a wide range of hard and soft skills that enhance the student learning experience because students can collaborate by testing 'what if' business scenarios. 
Furthermore, it is reported that simulation games allow students to experience a valid representation of real world business issues (Faria, 2006) and that students' enthusiasm for simulation games is very positive (Vos \& Brennan, 2010) leading to increased student engagement (Strachan, 2011). Students themselves perceive that simulations are an effective learning method (Jennings, 2002) because they bridge the gap between theory and practice (Avramenko, 2012). However, it is unclear whether undergraduate students are aware of the employability skills they could potentially develop via a simulation.

Any attempt at defining 'employability skills' is clouded by the difficulty in collating a strict list of attributes that employers will agree on (Iuliana, Dragos, \& Mitran, 2014). The findings reported in this case study utilise the Confederation of British Industry (CBI, 2009) definition of employability skills because they are widely discussed by employers across the industries into which graduates seek employment. These skills include self-management, team working, business and customer awareness, problem solving, communication and literacy, application of numeracy, and the application of information technology. Underpinning these skills is a positive attitude: a 'can-do' approach, a readiness to take part and contribute openness to new ideas and a drive to make these happen. Whilst businesses often lament the perceived lack of graduate skills (Leitch, 2006; Wingrove, 2014), this may in part result from students being unable to identify and articulate what skills they have developed. This case study demonstrates that students can become more aware of and develop their employability skills through a business simulation game.

The aim of the study was to test whether an online business simulation game (SimVenture Evolution) could improve students' self-perceived employability skills. A mixed interpretative approach used two structured questionnaires - one before the simulation game began and one upon completion. The sample included undergraduate students from Southampton Solent University, London South Bank University and the University of Southampton from business and marketing subject areas.

Figure 9.2 presents the results collated from all the three universities, showing the change in self-perceived employability skills.

The most significant outcome was the awareness and development of students' problem-solving skills, followed by teamwork, business 


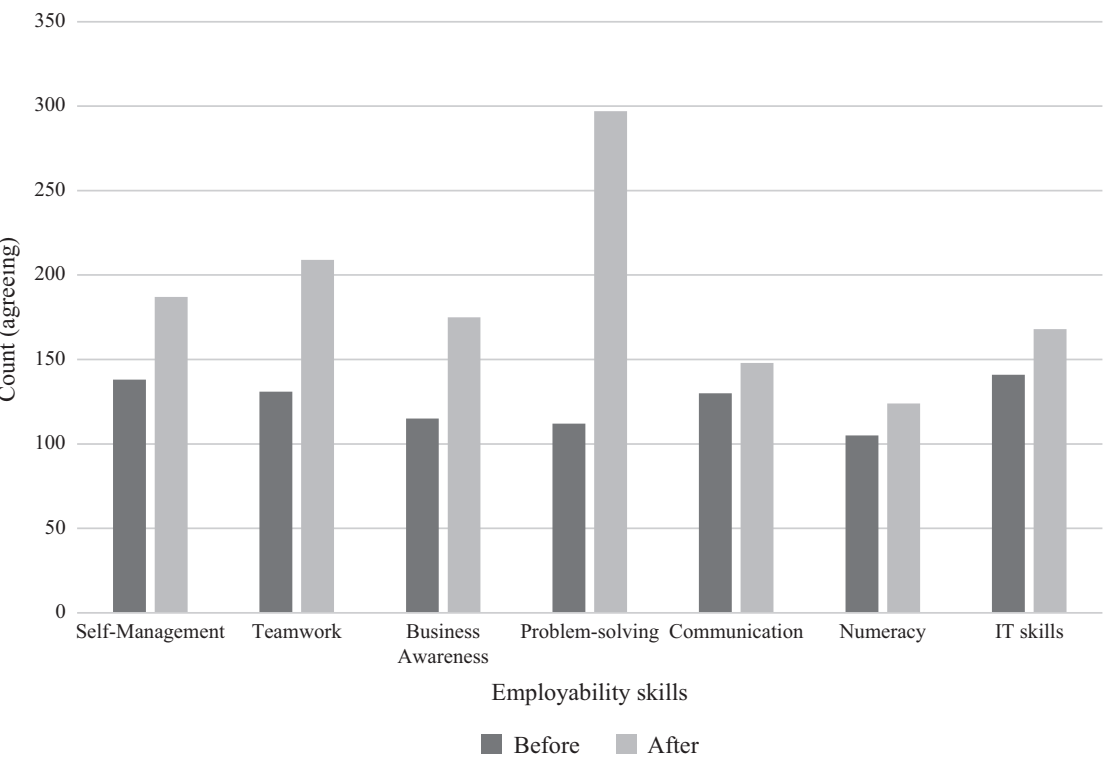

Fig. 9.2 Change in self-perceived employability skills

awareness and self-management. Qualitative feedback indicated that students were able to make an increased connection between theory and real-life contexts with comments such as 'I have been able to apply business theories to a real-life situation'. Importantly, students reported an increased awareness and development of all their employability skills. Since operating a business is not generally straight forward, students needed to develop a problem-solving approach to deal with the situations that evolved during the simulation, so the awareness and development of this skill is encouraging to see. The developments in teamwork skills were particularly interesting outcomes and may be as a result of students taking on Director roles as they work together to run their simulated company. This was something they found engaging and realistic and it was noticed by tutors that on many occasions, student teams would stay inrole after class to continue working on the simulation together. Other positive outcomes included attendance levels at $94 \%$ because students were 'actively involved', $77 \%$ of students reported a positive experience 
and assessment submission rates were $97 \%$. Tutors were also freed up to spend valuable time giving formative feedback to students.

Despite these positive outcomes, academic staff at the case universities did face some barriers to adoption: particularly institutional re-structuring and cost cutting, academic scepticism, and the difficulty of finding unbiased advice about suitable simulation games. The sharing of good practice and evidence which demonstrates that business simulations add value to the student learning experience and support the development of employability skills is likely to be a key factor in the continued adoption of such technology-based learning.

The benefits that simulations and games bring to learning result from a number of important and distinctive features. These features are discussed in turn below.

\section{Fidelity}

The level of fidelity achieved in a simulation or game concerns how closely it corresponds to the real world (Moizer et al., 2019). High-fidelity can be important to a simulation where transfer of knowledge learnt within the game to real world situations is required (Jones \& Bursens, 2015; Petridis et al., 2012), such as in the case of medical procedures. Some authors though contend that high levels of fidelity can distract students from learning, particularly in the context of computer-based serious games (Dankbaar et al., 2016). Some studies conclude that simplified games that strip out some of the aspects of complexity that exist in the real world can support more effective learning (Wright-Maley, 2015). By isolating and bringing to the fore the effect of key variables or drivers, simple simulations can benefit student understanding of processes or real world phenomena. Resultantly, links to theory taught in the classroom can be drawn out more readily (Avramenko, 2012) in a way that supports praxis (Ruggiero \& Watson, 2014). Perhaps counter-intuitively, it can be argued that simulations and games bring benefits to the field of real world learning because their ability to, in effect, simplify the real world can strengthen learning. By combining high levels of verisimilitude (i.e., how real a game or simulation 'feels') with a more tailored level of fidelity, 
student engagement can be sustained allowing such approaches to achieve impactful learning (Devine, 2016).

\section{Educator Control}

A notable feature of simulations and games is that, from an educator perspective, they bring benefits in terms of learning design and control (see, e.g., Arnab et al., 2015; Carvalho et al., 2015). For instance, in a role-play, educators are able to develop particular characters, settings and scenarios that best support the learning objectives of a particular module of study. Such a level of control may not be possible in real world situations. Furthermore, key aspects of the dynamics within a simulation or game can often be controlled by educators. For example, within a business simulation game, it is possible to introduce critical incidents such as a change in interest rates or exchange rates or even a global recession. Critical incidents such as these can have a powerful impact on learning, as they force students to reconfigure their thinking and behaviour as normal assumptions and routines are disrupted (Cope, 2003). Events of this nature may only occur infrequently in the real world or may not occur at times convenient for learning during the course of a particular module or programme (Lean, Moizer, \& Newbery, 2014). Through a simulation or game, students are able to experience an occurrence that they would be unlikely to encounter through other forms of real world learning. For instance, in the context of a business simulation game, they could see the impact of an exchange rate change on levels of demand for a product and implement responses accordingly, or in a computerised environmental management simulation, a natural disaster could be simulated to allow students to evaluate and implement appropriate responses.

A further aspect of educator control relates to feedback and reflection. Within a simulation or game, it is normally possible to 'pause' time and to design-in periods for debriefing, feedback or reflection (Crookall, 2010). In many real world situations, it can be challenging to include such interventions. Stepping out of a real world situation to reflect or receive feedback may simply not be practical. In addition, many computer-based simulations provide ongoing in-game feedback on 
performance. Such capabilities provide educators with multiple opportunities to harness the benefits of reflective learning (Bilgin, Baek, \& Park, 2015; Van der Meij, Leemkuil, \& Li, 2013). Case Study 3 highlights the importance of debriefing within a non-computerised simulation, focusing on the role that debriefing plays in supporting the feedforward of learning from a simulated setting to real world practice.

\section{Case Study 3}

Real-Time Immersive Simulation to Evaluate Students' Ability to Feedforward Their Learning from Simulation into Real-Life Practice (Cathrine Derham, Associate Dean (Education), School of Health Sciences, University of Surrey, UK)

Simulation enables students to safely practise skills and develop knowledge in a learning environment that closely replicates clinical practice (Cook, 2014). Real-time immersive simulation is a pedagogic approach which immerses students in real-life situations that require them to act, behave and think as if in clinical practice (Lopreiato et al., 2016). In response to students' requests for additional preparation prior to final clinical placements, a real-time immersive simulation event was introduced into a BSc Nursing Studies programme at the University of Surrey. Students from three fields of nursing took part in the learning experience. Three clinical settings were developed: ward settings for adult and child, field nursing students, and a drop-in environment for people experiencing mental health issues. These environments enabled students to experience scenarios relevant to their own area of practice.

The simulation event lasted one and a half hours and consisted of approximately 15 parallel scenarios which enabled the inclusion of the different nursing subspecialties. Students were asked to act as newly qualified nurses whilst caring for their patients and managing the clinical environments. If students wanted additional clinical support, they could phone switchboard to make this request. Patients, relatives, carers, doctors and outreach teams were played by academic staff, practice partners and actors. Students cared for patients and managed the situations they found themselves in, as if they were working in real world practice. The 
simulation was followed by a debriefing session which was facilitated by an experienced practitioner. The facilitator used open-ended statements to encourage discussion and used observational data taken during the simulation to prompt and guide feedback. The debriefing process is a vital component of learning via simulated practice. Facilitated discussion and reflection helps students to recontextualise their experiences (Evans, Guile, Harris, \& Allan, 2010) and apply their learning to the real world setting. The overall aim of this immersive simulated experience was to enable learning which would inform future practice in the real world setting and would therefore represent learning gain. Learning gain was defined as an improvement in knowledge, skills, work-readiness and personal development (Office for Students, n.d.) which resulted from the students' own unique and individual involvement in the immersive simulation.

To ascertain whether learning gain had been achieved, research using a mixed-methods approach was carried out (Morley, Bettles, \& Derham, 2019). Students recognised the immersive simulation event as a valuable learning opportunity and considered it had informed their professional development and preparation for practice. However, some students experienced difficulties in transferring learning from the simulated practice setting into the clinical environment. They identified barriers to the recontextualisation process (Evans et al., 2010), which impacted upon learning gain and the ability to feedforward learning. Barriers included a lack of individualised and personalised feedback during the group debriefing session and cautious and selective sharing of identified learning needs with mentors in the practice setting. Both impacted upon students' ability to further develop knowledge and skills and resulted in a disconnect between the two learning environments. Students who achieved successful workplace recontextualisation (Evans et al., 2010) were in a better position to achieve learning gain. These students tended to be proactive in their use of feedback and demonstrated self-regulatory behaviours, entering into a collaborative relationship with mentors, setting goals and plans for ongoing learning which was informed by their experiences during simulated practice.

It is important to recognise barriers and enablers which impact upon learning gain and this assists educators in the development of this 
approach and allows students to engage with and benefit from simulation pedagogy more successfully.

\section{Learning Through Mistakes}

Linked to the challenges of risk associated with many forms of real world learning, a key strength of simulations and games is that they allow students to learn through the process of making mistakes. Within simulations and games, learners typically make decisions or enact behaviours and are then able to see the outcomes of their actions. In contexts such as medicine, business and law the impacts of poor decisions or ill-conceived actions can be serious and, in the case of medicine, potentially life threatening. Yet, from a learning perspective, the lessons gained from mistakes are very powerful. Therefore, simulations and games provide learners with a 'safety net', allowing them to make decisions without fear of the potential negative outcomes. Such a safe environment enables students to experiment and try out ideas in a way that might not be possible in the real world. If things go wrong, nobody is hurt and the outcomes can be an important focus for reflective learning (Koivisto, Haavisto, Niemi, Katajisto, \& Multisilta, 2016; Kriz \& Manahl, 2016; Pariafsai, 2016).

\section{Double-Loop Learning}

A characteristic of simulations and games is that activities can be repeated such that students are able to experience a phenomenon on more than one occasion (Ebner \& Holzinger, 2007; Fortmüller, 2009; Pesare, Roselli, Corriero, \& Rossano, 2016). This brings particular benefits in terms of the depth of learning, with the potential for students to move from single-loop learning to double-loop learning. Argyris and Schön (1974, 1996) contend that single-loop learning occurs where learners operate within existing goals, plans and decision rules and do not question the governing variables that may affect a particular phenomenon. In contrast, double-loop learning occurs when experience leads to a shift in understanding, such that assumptions and goals change and mental 
models are adjusted. The ability to repeat simulations and games, such that learners see how their actions and decisions affect outcomes or performance through numerous cycles, enables students to learn from extended experience and recognise the limitations in their existing mental models (Moizer, Lean, Towler, \& Smith, 2006). Resultantly, they may change their approach to goal setting and planning (Kiili, 2007; Tao, Yeh, $\&$ Hung, 2015). Hence, such learning benefits may be readily attainable in a simulated environment but may be more challenging to achieve in other real world learning contexts.

\section{Challenges of Using Simulations and Games}

The advantages of using simulations and games for learning across a range of higher education disciplines are numerous and the capacity of such techniques to extend the reach of real world learning is clear. However, employing simulations and games is not without challenges. Whilst their use has become significantly more widespread in recent years, there are a variety of reasons why some educators may remain reluctant to employ simulations and games.

Lean et al. (2006) draw on previous literature to identify three key categories of potential barrier that represent challenges to the use of simulations and games by educators within Higher Education. The first relates to the risk of the unknown: that is, a reluctance amongst instructors to try new teaching approaches and a lack of awareness regarding the range of simulation and game options available. Educators may naturally be concerned about things going wrong when using new approaches, particularly where there is a perceived risk of technical problems that might affect the student learning experience. In an educational environment where student evaluation of instructors has become increasingly important, some educators may be inclined to stay with tried and tested learning approaches. Nevertheless, it remains the case that simulations and games provide a relatively safe environment for learning; a technical problem with an online business game may have an impact upon students' classroom experience, but this may be considered manageable compared to a significant financial loss which might be incurred if 
students were tasked to run a comparable business in the real world. A further consideration relating to this category of barrier concerns awareness. Despite the growing range of simulations and games that have been developed across a variety of subject areas, with many available 'off-theshelf' and ready to use, a simple lack of awareness amongst educators about the options available may inhibit their use (Diehl, de Souza, Gordan, Esteves, \& Coelho, 2014; Pei Rui Chan \& Zary, 2019).

The second category of barrier identified by Lean et al. (2006) concerns resource. For example, the need for time to develop simulations and games, or to become proficient in using them, is an important consideration. Using simulations and games is not an easy option; even the most advanced computer-based games are not self-teaching. Even though they are often pre-designed by others, preparing to use a particular simulation or game typically requires a considerable time commitment on the part of instructors for front-end planning and familiarisation (EgenfeldtNielsen, 2004). Additional resource considerations might include the availability of technical support and any costs associated with the purchase of materials, online access or physical resources such as computer hardware (McGrath et al., 2018; Usherwood, 2015). Whilst such costs may be only a fraction of those that may be incurred if students undertook activities for real, they can still be significant in some cases and may represent an obstacle to implementation (Bhagat, Liou, \& Chang, 2016).

A third barrier category discussed by Lean et al. (2006) relates to suitability. Modules and programmes of study in higher education are centred around the attainment of specified learning outcomes. Any learning activity within a given module or programme must be aligned with learning outcomes and, where appropriate, formative or summative assessment. Therefore, a key challenge for educators is to identify, or develop, simulations and games that are appropriate to achieving the learning outcomes of their module (Biagi \& Loi, 2013; Terras \& Boyle, 2019). Whilst many of the more generic modules on popular study programmes are increasingly well served by simulations and games that are available commercially or for free, for some subject areas, it may simply be that case that suitable learning resources are not available or are not sufficiently tailored to the specific requirements of a module. In addition to considering learning outcomes, educators make judgements about suitability in 
terms of how students may react to a given approach to learning. In the case of simulations and games, these techniques may be novel to some students and evidence suggests that learner perceptions of them are not homogenous. Whilst many students embrace them, some have been shown to exhibit more negative responses particularly around how the IT aspects of a game operate (Burdon \& Munro, 2017; Mayrath, Traphagan, Heikes, \& Trivedi, 2011).

Interestingly, survey evidence collected from instructors from a UK university indicates that factors associated with suitability, alongside concerns related to risk, represent the most significant issues in the use of simulations and games (Lean et al., 2006). This suggests that whilst challenges linked to the availability of time and other resources exist, they can often be overcome. Thus, the major considerations for educators are, perhaps as they should be, associated with academic judgements linked to the learning experience of students. That is, are available techniques suitable in relation to the aims of a given module and will the learning activity run smoothly and effectively from a student perspective?

In the concluding section of this chapter, the implications of simulations and games for pedagogical practice in the field of real world learning are explored alongside some recommendations for further research.

\section{Conclusion: Implications for Practice and Research}

Simulations and games, in all their various forms, offer Higher Education educators considerable scope to enrich the learning experience of students. As demonstrated by the case studies presented in this chapter, they can be applied across a wide range of subjects and in a variety of diverse learning contexts. They provide a solution to some of the key barriers to real world learning, namely risk, cost and timescale. Further, simulations and games bring advantages associated with levels of fidelity and educator control and their capacity to support learning through allowing mistakes to be made by students. They also allow double-loop learning to occur as students' mental models of the world develop. As a bridge between 
traditional learning and real world learning, they enable educators to facilitate realistic insights into practice whilst maintaining many of the benefits of class-based activity.

Nevertheless, as with any pedagogical approach, there are challenges associated with using simulations and games. These need to be understood and managed by educators to ensure effective learning. A key issue for educational practice is the importance of initial assessment of techniques in terms of their suitability for addressing learning outcomes and providing an engaging experience for students within a given subject or learning context. Gaining an awareness of the range of existing options is an important first step, and given the disparate nature of information available, the time required to research and try out alternative techniques is not to be underestimated. Further, it may be that, where suitable options are limited, customisation or bespoke development may be required. Even where this is not required, significant up-front familiarisation and planning is typically needed ahead of implementation. As is common with other forms of real world learning, the need for careful pre-planning takes a significant investment in time and energy; and this doesn't stop once the simulation or gaming activity begins. Such techniques are not self-teaching but require ongoing engagement by educators. This may involve progress monitoring, various learning interventions, in-activity feedback and post-activity debriefing and reflection.

Despite the significant efforts required in using simulations and games, the learning benefits can be substantial. Still, it is also true to say that empirical evidence on the impacts of simulations and games in Higher Education is currently limited. Whilst there is a growing body of research (see, e.g., the 2015 Special Issue of the International Journal of Management Education-Lean et al., 2015), a need exists to understand how such approaches affect learning and other desirable outcomes relevant to different fields of practice. For example, these may include employability skills, entrepreneurial intent and subject-specific technical skills. In addition, very little current research examines how the benefits of simulations and games might be enhanced to support even more effective learning. For instance, how does assessment design affect learning through simulations? What is the role of reflective debriefing and how can this be leveraged to best effect? How can the learning benefits of simulation be 
enhanced through the use of critical incidents? How do group dynamics influence learning in a team game? Such questions ensure that there are rich opportunities for further important pedagogical research contributions in this field. As the range of applications of simulations and games grows and further empirical evidence is accumulated, our understanding of the role of such techniques within the realm of real world learning will undoubtedly increase, enabling the development of more effective learning.

\section{References}

Al-Elq, A. H. (2010). Simulation-based medical teaching and learning. Journal of Family \& Community Medicine, 17(1), 35-40. https://doi. org/10.4103/1319-1683.68787

Argyris, C., \& Schön, D. (1974). Theory in practice: Increasing professional effectiveness. San Francisco, CA: Jossey-Bass.

Argyris, C., \& Schön, D. (1996). Organisational learning II. New York: Addison-Wesley.

Arnab, S., Lim, T., Carvalho, M. B., Bellotti, F., De Freitas, S., Louchart, S., ... De Gloria, A. (2015). Mapping learning and game mechanics for serious games analysis. British Journal of Educational Technology, 46(2), 391-411. https://doi.org/10.1111/bjet.12113

Avramenko, A. (2012). Enhancing students' employability through business simulation. Education+Training, 54(5), 355-367. https://doi. org/10.1108/00400911211244669

Baptista, G., \& Oliveira, T. (2018). Gamification and serious games: A literature meta-analysis and integrative model. Computers in Human Behavior, 92, 306-315. https://doi.org/10.1016/j.chb.2018.11.030

Barnett, M. (2004). Risk Management training: The development of simulatorbased scenarios from the analysis of recent maritime accidents. In Proceedings of the Advances in International Maritime Research Conference. Tasmania: IAMU Tasmania.

Bhagat, K. K., Liou, W. K., \& Chang, C. Y. (2016). A cost-effective interactive $3 \mathrm{D}$ virtual reality system applied to military live firing training. Virtual Reality, 20(2), 127-140. https://doi.org/10.1007/s10055-016-0284-x 
Biagi, F., \& Loi, M. (2013). Measuring ICT use and learning outcomes: Evidence from recent econometric studies. European Journal of Education, 48(1), 28-42. https://doi.org/10.1111/ejed.12016

Bilgin, C. U., Baek, Y., \& Park, H. (2015). How debriefing strategies can improve student motivation and self-efficacy in game-based learning. Journal of Educational Computing Research, 53(2), 155-182. https://doi. org/10.1177/0735633115598496

Bloom, B. S. (Ed.). (1956). Taxonomy of educational objectives. Vol. 1: Cognitive domain. New York: McKay.

Boyle, E. A., Hainey, T., Connolly, T. M., Gray, G., Earp, J., Ott, M., ... Pereira, J. (2016). An update to the systematic literature review of empirical evidence of the impacts and outcomes of computer games and serious games. Computers \&Education, 94, 178-192. https://doi.org/10.1016/j.compedu.2015.11.003

Burdon, W. M., \& Munro, K. (2017). Simulation-is it all worth it? The impact of simulation from the perspective of accounting students. The International Journal of Management Education, 15(3), 429-448. https://doi.org/10.1016/j. ijme.2017.07.001

Carvalho, M. B., Bellotti, F., Berta, R., De Gloria, A., Sedano, C. I., Hauge, J. B., ... Rauterberg, M. (2015). An activity theory-based model for serious games analysis and conceptual design. Computers \& Education, 87, 166-181. https://doi.org/10.1016/j.compedu.2015.03.023

CBI. (2009, March 26). Future fit-Preparing graduates for the world of work. Retrieved from https://www.universitiesuk.ac.uk/policy-and-analysis/ reports/Documents/2009/future-fit-preparing-graduates-for-the-worldof-work.PDF

Clarke, E. (2009). Learning outcomes from business simulation exercises. Education \& Training, 51(5/6), 448-459. https://doi. org/10.1108/00400910910987246

Cook, D. A. (2014). How much evidence does it take? A cumulative metaanalysis of outcomes of simulation-based education. Medical Education, 48(8), 750-760. https://doi.org/10.1111/medu.12473

Cope, J. (2003). Entrepreneurship learning and critical reflection: Discontinuous events as triggers for 'higher-level' learning. Management Learning, 34(4), 429-450. https://doi.org/10.1177/1350507603039067

Crookall, D. (2010). Serious games, debriefing, and simulation/gaming as a discipline. Simulation \& Gaming, 41(6), 898-920. https://doi. org/10.1177/1046878110390784 
Dankbaar, M. E., Alsma, J., Jansen, E. E., van Merrienboer, J. J., van Saase, J. L., \& Schuit, S. C. (2016). An experimental study on the effects of a simulation game on students' clinical cognitive skills and motivation. Advances in Health Sciences Education, 21(3), 505-521. https://doi.org/10.1007/ s10459-015-9641-x

Devine, J. (2016). Real enough? Realism and simulation design in the political science classroom. In L. Wasylkiw \& J. L. Tomes (Eds.), Mount A Teaches (pp. 121-134). Canada, BC: Friesen Press.

Diehl, L. A., de Souza, R. M., Gordan, P. A., Esteves, R. Z., \& Coelho, I. C. M. (2014). Gaming habits and opinions of Brazilian medical school faculty and students: What's Next? Games for Health Journal: Research, Development, and ClinicalApplications, 3(2), 79-85. https://doi.org/10.1089/ g4h.2013.0069

Ebner, M., \& Holzinger, A. (2007). Successful implementation of user-centered game based learning in higher education: An example from civil engineering. Computers \& Education, 49(3), 873-890. https://doi.org/10.1016/j. compedu.2005.11.026

Egenfeldt-Nielsen, S. (2004). Practical barriers in using educational computer games. On The Horizon, 12(1), 18-21. https://doi. org/10.1108/10748120410540454

Ellman, N. (1977). Before the simulation fails: Avoiding potential pitfalls. Social Studies, 68(6), 251-253.

Evans, K., Guile, D., Harris, J., \& Allan, H. (2010). Putting knowledge to work: A new approach. Nurse Education Today, 30(3), 245-251. https://doi. org/10.1016/j.nedt.2009.10.014

Faria, A. J. (2006). History, current usage, and learning from marketing simulation games: A detailed literature review. Proceedings of the Marketing Management Association, 138-139.

Fortmüller, R. (2009). Learning through business games: Acquiring competences within virtual realities. Simulation \& Gaming, 40(1), 68-83. https:// doi.org/10.1177/1046878107308075

Gatfield, D. (2006). Engine room simulator instructor course, Session 10/2. Carrying out a simulator exercise: Debriefing. METNET.

Goi, C. L. (2019). The use of business simulation games in teaching and learning. Journal of Education for Business, 94(5), 342-349. https://doi.org/10.108 0/08832323.2018.1536028

Gopinath, C., \& Sawyer, J. E. (1999). Exploring the learning from an enterprise simulation. Journal of Management Development, 18(5), 477-489. 
Hainey, T., Connolly, T. M., Stansfield, M., \& Boyle, E. A. (2011). Evaluation of a game to teach requirements collection and analysis in software engineering at tertiary education level. Computers \& Education, 56, 21-35. https:// doi.org/10.1016/j.compedu.2010.09.008

Hogg, E. S., Kinshuck, A. J., Littley, N., Lau, A., Tandon, S., \& Lancaster, J. (2019). A high-fidelity, fully immersive simulation course to replicate ENT and head and neck emergencies. The Journal of Laryngology \& Otology, 133(2), 115-118. https://doi.org/10.1017/S0022215118002347

Hollon, S. D., \& Beck, A. T. (1994). Cognitive and cognitive-behavioral therapies. In A. E. Bergin \& S. L. Garfield (Eds.), Handbook of psychotherapy and behavior change (pp. 428-466). New York: Wiley.

Ibrahim, R., Masrom, S., Yusoff, R. C. M., Zainuddin, N. M. M., \& Rizman, Z. I. (2017). Student acceptance of educational games in higher education. Journal of Fundamental and Applied Sciences, 9(3S), 809-829. https://doi. org/10.4314/jfas.v9i3s.62

Iuliana, P., Dragos, M. I., \& Mitran, P. C. (2014). Identification of employability skills - Starting point for the curriculum design process. Economics, Management \& Financial Markets, 9(1), 237-246.

Jennings, D. (2002). Strategic management: An evaluation of the use of three learning methods. The Journal of Management Development, 21(9), 655-665. https://doi.org/10.1108/02621710210441658

Jones, R., \& Bursens, P. (2015). The effects of active learning environments: How simulations trigger affective learning. European Political Science, 14, 254-265. https://doi.org/10.1057/eps.2015.22

Keys, B., \& Wolfe, J. (1990). The role of management games and simulations in education and research. Journal of Management, 16(2), 307-336. https://doi. org/10.1177/014920639001600205

Kiili, K. (2007). Foundation for problem-based gaming. British Journal of Educational Technology, 38(3), 394-404. https://doi. org/10.1111/j.1467-8535.2007.00704.x

Koivisto, J. M., Haavisto, E., Niemi, H., Haho, P., Nylund, S., \& Multisilta, J. (2018). Design principles for simulation games for learning clinical reasoning: A design-based research approach. Nurse Education Today, 60, 114-120. https://doi.org/10.1016/j.nedt.2017.10.002

Koivisto, J. M., Haavisto, E., Niemi, H., Katajisto, J., \& Multisilta, J. (2016). Elements explaining learning clinical reasoning using simulation games. International Journal of Serious Games, 3(4), 29-43. https://doi.org/10.17083/ ijsg.v3i4.136 
Kriz, W. C., \& Manahl, W. (2016). Understanding and changing systems through hybrid simulation game design methods in educational contexts. In T. Kaneda, H. Kanegae, P. Rizzi, \& Y. Toyoda (Eds.), Simulation and Gaming in the Network Society. Translational Systems Sciences (Vol. 9, pp. 79-93). Singapore: Springer. https://doi.org/10.1007/978-981-10-0575-6_7

Lean, J., Moizer, J., \& Newbery, R. (2014). Enhancing the impact of online simulations through blended learning: A critical incident approach. Education \& Training, 56(2/3), 208-218. https://doi.org/10.1108/ET-01-2013-0007

Lean, J., Moizer, J., Towler, M., \& Abbey, C. (2006). Simulations and games: Use and barriers in higher education. Active Learning in Higher Education, 7(3), 227-242. https://doi.org/10.1177/1469787406069056

Lean, J., Moizer, J., \& Warren, M. (2015). The use and impact of simulations in management education. International Journal of Management Education, 13(3), 349. https://doi.org/10.1016/j.ijme.2015.11.001

Leitch, S. (2006, December). Prosperity for all in the global economy: World class skills: Final report. TSO (The Stationery Office). Retrieved from http://www. official-documents.gov.uk/document/other/0118404792/0118404792.pdf

Lopreiato, J. O., Downing, D., Gammon, W., Lioce, L., Sittner, B., Slot, V., \& Spain, A. E. (2016, June). Healthcare Simulation Dictionary. Society for Simulation in Healthcare. Retrieved from http://www.ssih.org/dictionary

Marda, M., Economou, D., \& Bouki, V. (2018). Enhancing deeper learning using empathy and creativity in serious games role-play simulations. In European Conference on Games Based Learning (pp. 785-791). Brighton: Academic Conferences International Limited.

Mayrath, M. C., Traphagan, T., Heikes, E. J., \& Trivedi, A. (2011). Instructional design best practices for Second Life: A case study from a college-level English course. Interactive Learning Environments, 19(2), 125-142. https://doi. org/10.1080/10494820802602568

McCall, J. (2016). Teaching history with digital historical games: An introduction to the field and best practices. Simulation \& Gaming, 47(4), 517-542. https://doi.org/10.1177/1046878116646693

McGrath, J. L., Taekman, J. M., Dev, P., Danforth, D. R., Mohan, D., Kman, N., ... Talbot, T. B. (2018). Using virtual reality simulation environments to assess competence for emergency medicine learners. Academic Emergency Medicine, 25(2), 186-195. https://doi.org/10.1111/acem.13308

McGrath, M., Harris, A., \& Whitelaw, P. A. (2016). Scaffolding a destination simulation into an undergraduate hospitality and tourism program. In M. Scerri \& L. K. Hui (Eds.), CAUTHE 2016: The Changing Landscape of 
Tourism and Hospitality: The Impact of Emerging Markets and Emerging Destinations (pp. 1133-1139). Sydney: Blue Mountains International Hotel Management School.

Moizer, J., \& Lean, J. (2010). Toward endemic deployment of educational simulation games: A review of progress and future recommendations. Simulation \& Gaming, 41(1), 116-131. https://doi.org/10.1177/1046878109359052

Moizer, J., Lean, J., Dell'Aquila, E., Walsh, P., Keary, A. A., O’Byrne, D., ... Friedrich, R. (2019). An approach to evaluating the user experience of serious games. Computers and Education, 136, 141-151. https://doi. org/10.1016/j.compedu.2019.04.006

Moizer, J., Lean, J., Towler, M., \& Smith, G. (2006). Modes of learning in the use of a computer-based business simulation game. International Journal of Learning Technology, 2(1), 49-61. https://doi.org/10.1504/ IJLT.2006.008692

Morley, D., Bettles, S., \& Derham, C. (2019). The exploration of students' learning gain following immersive simulation - The impact of feedback. Higher Education Pedagogies, 4(1), 368-384. https://doi.org/10.108 $0 / 23752696.2019 .1642123$

Narayanan, E., \& Turner, J. J. (2019). Perceptions of simulation games and the role they play in creating an enterprising and employable graduate. International Journal of Education, Psychology and Counseling, 4(30), 179-196.

Newbery, R., Lean, J., Moizer, J., \& Haddoud, M. (2018). Entrepreneurial identity formation during the initial entrepreneurial experience: The influence of simulation feedback and existing identity. Journal of Business Research, 85, 51-59. https://doi.org/10.1016/j.jbusres.2017.12.013

Nicol, D. J., \& Macfarlane-Dick, D. (2006). Formative assessment and selfregulated learning: A model and seven principles of good feedback practice. Studies in Higher Education, 31(2), 199-218. https://doi. org/10.1080/03075070600572090

Office for Students. (n.d.). Learning Gain. Retrieved from https://www.officeforstudents.org.uk/advice-and-guidance/teaching/learning-gain/

Pallis, A. A., \& Ng, A. K. (2011). Pursuing maritime education: An empirical study of students' profiles, motivations and expectations. Maritime Policy \& Management, 38(4), 369-393. https://doi.org/10.1080/0308883 9.2011 .588258

Pariafsai, F. (2016). Effectiveness of a virtual project-based simulation game in construction education. International Journal of Scientific Research in Science, Engineering and Technology, 2(5), 377-393. 
Pavlov, P. I. (2010). Conditioned reflexes: An investigation of the physiological activity of the cerebral cortex. Annals of Neurosciences, 17(3), 136-141. https://doi.org/10.5214/ans.0972-7531.1017309

Pei Rui Chan, K., \& Zary, N. (2019). Knowledge, use and barriers to Serious Games in undergraduate medical education. https://doi.org/10.31219/ osf.io/2f7rw

Pesare, E., Roselli, T., Corriero, N., \& Rossano, V. (2016). Game-based learning and gamification to promote engagement and motivation in medical learning contexts. Smart Learn Environments, 3(5). https://doi.org/10.1186/ s40561-016-0028-0

Petridis, P., Dunwell, I., Arnab, S., Protopsaltis, A., Hendrix, M., \& de Freitas, S. (2012). Game engines selection framework for high-fidelity serious applications. International Journal of Interactive Worlds, 2012, 1-19. https://doi. org/10.5171/2012.418638

Ruggiero, D., \& Watson, W. R. (2014). Engagement through praxis in educational game design common threads. Simulation \& Gaming, 45(4-5), 471-490. https://doi.org/10.1177/1046878114553570

Scholtz, F., \& Hughes, S. (2019). A systematic review of educator interventions in facilitating simulation based learning. Journal of Applied Research in Higher Education. https://doi.org/10.1108/JARHE-02-2018-0019

Skinner, B. F. (2011). About behaviorism. New York: Knopf Doubleday.

Stern, N. (2016). Building on success and learning from experience: An independent review of the research excellence framework. London: Department for Business, Energy and Industrial Strategy.

Strachan, L. (2011). Do business simulation games improve a graduate's employability? Graduates with Impact: Through Excellence in Business Education Conference. 10th March 2011. Bournemouth.

Strachan, L. (2016). Teaching employability skills through simulation games. Journal of Pedagogic Development, 6(2), 8-17.

Subhash, S., \& Cudney, E. A. (2018). Gamified learning in higher education: A systematic review of the literature. Computers in Human Behavior, 87, 192-206. https://doi.org/10.1016/j.chb.2018.05.028

Tai, J. H. M., Canny, B. J., Haines, T. P., \& Molloy, E. K. (2017). Implementing peer learning in clinical education: A framework to address challenges in the "real world". Teaching and Learning in Medicine, 29(2), 162-172. https:// doi.org/10.1080/10401334.2016.1247000 
Tao, Y. H., Yeh, C. C. R., \& Hung, K. C. (2015). Validating the learning cycle models of business simulation games via student perceived gains in skills and knowledge. Educational Technology \& Society, 18(1), 77-90.

Terras, M. M., \& Boyle, E. A. (2019). Integrating games as a means to develop e-learning: Insights from a psychological perspective. British Journal of Educational Technology, 50(3), 1049-1059. https://doi.org/10.1111/ bjet. 12784

Usherwood, S. (2015). Building resources for simulations: Challenges and opportunities. European Political Science, 14, 218-227. https://doi. org/10.1057/eps.2015.19

Van der Meij, H., Leemkuil, H., \& Li, J.-L. (2013). Does individual or collaborative self-debriefing better enhance learning from games? Computers in Human Behavior, 29(6), 2471-2479. https://doi.org/10.1016/j. chb.2013.06.001

Vos, L., \& Brennan, R. (2010). Marketing simulation games: Student and lecturer perspectives. Marketing Intelligence \& Planning, 28(7), 882-897. https://doi.org/10.1108/02634501011086472

Vygotsky, L. (1978). Interaction between learning and development. Readings on the Development of Children, 23(3), 34-41.

Wingrove, L. (2014, December 10). Are graduates lacking the skills that employers need? Retrieved from https://www.trainingjournal.com/blog/ are-graduates-lacking-skills-employers-need

Wouters, P., \& van Oostendorp, H. (2017). Overview of instructional techniques to facilitate learning and motivation of serious games. In P. Wouters $\& \mathrm{H}$. van Oostendorp (Eds.), Instructional techniques to facilitate learning and motivation of serious games (pp. 1-16). New York: Springer. https://doi. org/10.1007/978-3-319-39298-1_1

Wright-Maley, C. (2015). Beyond the "Babel problem": Defining simulations for the social studies. The Journal of Social Studies Research, 39(2), 63-77. https://doi.org/10.1016/j.jssr.2014.10.001 
Open Access This chapter is licensed under the terms of the Creative Commons Attribution 4.0 International License (http://creativecommons.org/licenses/ by/4.0/), which permits use, sharing, adaptation, distribution and reproduction in any medium or format, as long as you give appropriate credit to the original author(s) and the source, provide a link to the Creative Commons licence and indicate if changes were made.

The images or other third party material in this chapter are included in the chapter's Creative Commons licence, unless indicated otherwise in a credit line to the material. If material is not included in the chapter's Creative Commons licence and your intended use is not permitted by statutory regulation or exceeds the permitted use, you will need to obtain permission directly from the copyright holder.

(c) 